\title{
NA ERA DA MULTIPLICIDADE: FRAGMENTAÇÃO, INTENSIDADE E VIOLÊNCIA NO ROMANCE AS FANTASIAS ELETIVAS
}

\author{
Rondinele Aparecido Ribeiro* \\ Francisco Cláudio Alves Marques *
}

\begin{abstract}
RESUMO: Os textos contemporâneos podem ser apresentados sob o rótulo da rapidez, da concisão e da brevidade. Dessa forma, predomina uma multiplicidade de tendências e de formas que não necessariamente precisam se sobrepor uma a outra, mas sim conviverem de maneira harmônica. A partir dessas considerações iniciais, este artigo se propõe a analisar o romance As Fantasias Eletivas. Para tanto, buscamos estudar como ocorre a fragmentação, a intensidade e a violência nessa narrativa. Como subsídios teóricos, foram utilizados os trabalhos de Antonio Candido (1987; 2003), Beatriz Resende (2008; 2015), Tânia Pellegrini (2008), Ana Paula Franco Nobile Brandileone (2013), dentre outros.
\end{abstract}

PALAVRAS-CHAVE: Literatura Brasileira contemporânea; Fragmentação; Identidade; Violência.

\section{Introdução}

A literatura, como atesta Antonio Candido (2003), notabiliza-se por apresentar um viés artístico e estético responsável por atuar como um mecanismo de humanização devido sua peculiaridade em se constituir como fonte de educação humanizadora do homem revelada pela potencialidade de se manifestar esteticamente permitindo ao leitor experimentar uma realidade, às vezes, bastante diferente da sua, o que revela seu traço característico

\footnotetext{
* Mestrando do Programa de Pós-graduação em Letras da Universidade Estadual Paulista Júlio de Mesquita Filho (Unesp).

${ }^{* *}$ Doutor em Letras pela Universidade de São Paulo (Usp). Professor de Letras da Universidade Estadual Paulista Júlio de Mesquita Filho (Unesp).
} 
de ampliar os horizontes de expectativas dos sujeitos. Dessa forma, essa manifestação artística é responsável por estimular o senso crítico além de se atrelar a um espaço propiciador das mais diversas reflexões devido a sua potencialidade em representar os conflitos humanos, tornando-os palpáveis ao leitor.

Enquanto materialidade discursiva, a literatura notabiliza-se pela sua inscrição em um contexto sociocultural específico, tanto é que Candido (2003) salienta sua ligação com o caráter expressivo de um determinado grupo num tempo ou num espaço, uma vez que ela "[...] confirma o homem na sua humanidade, inclusive porque atua em grande parte no seu subconsciente e no inconsciente” (CANDIDO, 2003, p. 243).

Se um breve diagnóstico pode ser dado acerca da literatura brasileira contemporânea, ele revelará que essa produção artística se constituiu como um espaço diversificado de manifestações amplificado pela preponderância da inserção no país no cenário da globalização revelador, como atesta Beatriz Resende (2010), de um mundo de fluxos caracterizado pela existência de objetos em movimento em seu estado de fluidez. "E esses objetos incluem ideologias, povos, mercadorias, imagens e mensagens, tecnologias e técnicas. É o que chamo de um mundo de fluxos" (RESENDE, 2010, p. 103). A autora destaca que mesmo o conceito de estado-nação, tido como um conceito estável, releva-se como um espaço notoriamente perpassado pela fluidez. Nas palavras da autora: "Mesmo aquele que pode parecer o mais estável desses objetos - o estado-nação - é frequentemente caracterizado por populações em movimento, fronteiras questionadas, configurações, habilidades e tecnologias móveis" (RESENDE, 2010, p. 103-104). Assim, a partir do ponto de vista da estudiosa, compreender a narrativa ficcional desse período como inscrita no cenário marcado pela globalização de tal modo a se reverberar num movimento de rompimento com as referências espaciais meramente locais.

Para a autora, essa mobilidade em tempos de fluxos globais avança até o ponto de incluir em sua fluidez a imaginação. Como a literatura está ligada a uma realidade cultural complexa, dialoga com o cotidiano vivido, matéria que inspira o escritor a tecer seu véu ficcional, mostrando que sua manifestação discursiva reflete e refrata essa realidade na qual 
foi inspirada. Ao situar a imaginação nesse cenário de fluxos, Resende (2010) evidencia não se tratar mais de um conceito compreendido como o resultado de gênio individual ou apenas como uma dimensão estética.

Ao enfatizar a faculdade da imaginação marcada pela inspiração no cotidiano vivido, a autora afirma:

É a faculdade que dá forma à vida do homem comum de maneiras as mais diversas. É o que faz com que as pessoas pensem em emigrar ou viajar, o que as faz resistir à violência, redesenhar suas vidas, buscar novas formas de associação e colaboração, muitas vezes para além das fronteiras nacionais (RESENDE, 2010, p. 104).

No que tange à manifestação discursiva da literatura contemporânea, cabe assinalar, no âmbito da crítica literária, os vários estudos empreendidos acerca da forma de apresentação dessa manifestação artística no século XXI. Nesse rol, podem ser apresentados os estudos empreendidos por Antonio Candido (1987; 2003), Beatriz Resende (2008; 2010), Ana Paula Franco Nóbile Brandileone (2013) e Maria Zilda Cury (2007). Esses pesquisadores fornecem uma verdadeira cartografia acerca de nossa produção recente, além de apresentar as singularidades da fértil literatura produzida nesse cenário marcado por inúmeros fluxos.

Ao assinalar, ainda que de maneira transitória, um diagnóstico para o vasto conjunto da produção literária atual, Resende (2008) aponta como aspectado caracterizador a multiplicidade, afinal, a ficção contemporânea se releva pelo escaninho da diversidade revelada por múltiplos gêneros, por múltiplas formas de divulgação da escrita e, sobretudo, por inúmeros escritores, o que acaba por desnudar a fertilidade do meio literário. Dito isso, para justificar a preponderância da multiplicidade como característica da produção contemporânea, a crítica destaca o surgimento de novos escritores e a efervescência do mercado editorial brasileiro, revelando que no país se produz e se consome muita literatura.

Outro fenômeno apontado por Resende (2008) é a reconfiguração das formas de disseminar a escrita literária, uma vez que devido às especificidades dos suportes digitais, autores ausentes dos circuitos editorias encontram nesse meio uma forma riquíssima de se 
inserir no meio literário até serem recrutados pelas grandes editoras. Além disso, nos últimos anos, vale ressaltar, o surgimento de prêmios literários com gratificações bem mais atrativas que no passado. O ponto de vista de Resende (2008) concebe a multiplicidade como heterogeneidade revelada na linguagem, nos formatos bem como na relação autorleitor, nos temas, na reconfiguração sobre o que é literatura e, ainda, no suporte, que não mais se limita ao meio impresso.

A autora apresenta, nesse contexto, três aspectos dominantes: a presentificação vista como a urgência e a forte preocupação com o presente revelada nos temas nas formas; a presença do trágico e o emprego da violência, que se revela "na urgência da presentificação e na dominância do trágico e, angústia recorrente, com a inserção do autor contemporâneo na grande cidade, na metrópole imersa numa realidade temporal de trocas tão globais quanto barbaramente desiguais" (RESENDE, 2008, p. 33).

Assim, a ênfase nessa diversidade acaba sendo responsável pelo traço diferenciador desse momento como atesta Brandileone (2013). O ponto de vista da estudiosa em atribuir à literatura contemporânea a marca da diversidade se explica também pela pluralidade de tendências:

E um dos traços dessa diversidade está no fato de que não há na literatura produzida a partir das décadas de 80 e 90 um projeto estético ou político único, cujos traços possibilitem defini-la sob um rótulo, como é o caso, por exemplo, da literatura produzida durante a ditadura militar que já é, consensualmente denominada "literatura pós-64"; ou então de outros movimentos estéticos como os que congregaram os modernistas e/ou poetas concretistas, em que se conseguia vislumbrar um projeto literário comum (BRANDILEONE, 2013, p. 18).

Sobresssai no ponto de vista da autora a concepção de que a condição da literatura brasileira atual está fortemente atrelada ao espaço plural de produções haja vista não se ter a possibilidade de vislumbrar a constituição de um grupo com características uniformes. Como consequência dessa particularidade, o texto literário acaba incorporando essa multiplicidade de temas, de gêneros, de suportes, de linguagens e de divulgação. Para Brandile- 
one (2013), a crítica literária se mostra bastante cética acerca dos contornos da vasta produção literária, sobretudo, pela observação do reflexo dessa heterogeneidade de temas e de formas. De modo geral, como esclarece a autora, evita-se lançar prognósticos equivocados acerca da qualidade dessa literatura bem como dos escritores que figurarão no cânone.

Outra autora que traz sua contribuição para a compreensão dessa particularidade da literatura contemporânea é Maria Zilda Cury (2007). A estudiosa enfatiza que a grande dificuldade encontrada para se caracterizar e classificar a vasta produção do período atual remonta ao fato de o escritor ser uma figura bastante ativa na sociedade e produzir a obra no mesmo momento em que ficcionaliza essa realidade, além de estar muito próximo do leitor temporal e espacialmente. Para a crítica, esse aspecto revela o traço da impossibilidade de se identificar uma vertente fundadora da produção literária contemporânea. “Além disso, diferentemente da criação poética cujo marco hegemônico no Brasil é o Modernismo-, é claro, com linhas dele decorrentes muito variadas e distintas -, a produção contemporânea em prosa não tem, digamos assim e grosso modo, uma vertente fundadora" (CURY, 2007, p. 08).

\section{Fragmentação, intensidade e violência em As fantasias eletivas}

Ao atribuir à literatura contemporânea a característica da multiplicidade, Resende (2010) elenca três tendências preponderantes no conjunto ficcional produzido a partir dos anos 2000: narrativas que apresentam reflexões sobre a formação do Brasil moderno, as quais propõem uma interpretação sobre o país; narrativas que abordam o real com uma escrita ficcional envolvente e a escritura realista das cidades brasileiras imersas no cenário amplificado da violência reverberado pela desigualdade reinante no país. Para a pesquisadora, essa última tendência, revela-se como uma forte vocação para ser envolvida pela indústria cultural, contribuindo, dessa forma, para a propagação do texto literário e sua incorporação em outros meios de difusão, tais como o cinema e a televisão, suportes que têm 
se valido constantemente das narrativas atravessadas pela violência para formar um verdadeiro mapa de produções culturais assentadas nessa vertente como uma legítima expressão constitutiva cultural brasileira.

A crítica Tânia Pellegrini (2008), ao associar produção artística e contexto social, afirma que a violência se faz presente no cotidiano brasileiro de modo a se estabelecer como um elemento possibilitador da organização social, que está atrelada de forma visível a uma experiência reveladora e inerente de países de extração colonial. A autora salienta ainda que, ao longo da história literária brasileira, a violência foi retratada por meio de diferentes formas nos mais diversos gêneros e esteve associada a uma efervescência de temas, tais como o processo de colonização do país, o aniquilamento dos índios, a escravidão, a intensa luta pela independência, a constituição dos latifúndios, o processo de industrialização, a formação das metrópoles, o imperialismo e a instauração das ditaduras, dentre outros.

Sobre a matriz da violência nas narrativas brasileiras, pronuncia-se Pellegrini (2008, p. 41):

Há quem afirme que o conjunto da literatura brasileira atualmente exige novos modelos de análise, capazes de estimular novas leituras e interpretações, uma vez que a tendência à exacerbação da violência e da crueldade, com a descrição minuciosa de atrocidades, sevícias e escatologia, vem pontuando cada vez mais tanto narrativas literárias quanto as audiovisuais, do cinema ou da televisão. Como se a dramatização do princípio da violência passasse a ser diretriz principal da organização formal, com seu caráter inarredável e obsceno, subsumindo tempos e espaços, personagens e situações.

Acerca das múltiplas formas de manifestação da violência, a autora salienta o caráter ligado ao emprego da força com o intuito de causar dano físico ou psicológico a outrem, esbarrando-se, quase sempre, na problemática do crime. A partir do ponto de vista de Pellegrini (2008), compreendemos que a violência na cultura brasileira se faz presente desde a constituição do país e se revela como um elemento ligado à fundação da cultura brasileira. Dessa forma, esse tema se reverbera nas mais diversas manifestações culturais. Seja no cinema, na televisão ou na literatura, essa vertente figura como uma força intensa 
constituindo-se como uma forma de problematização do Brasil. “[...] Não se deseja emocionar ou suscitar a contemplação, mas causar choque no leitor e excitar a argúcia do crítico, por meio de textos que penetram com vigor, mas não se deixam avaliar com facilidade" (PELLEGRINI, 2008, p. 52).

A temática ligada à violência, caracterizadora da experiência urbana embrutecedora, reflete as consequências de uma sociedade cuja origem estrutura-se numa relação patriarcal e perpassa a desordem do processo de metropolização desordenado, consequência da globalização, que fez conviver em um mesmo espaço pessoas de diversas classes sociais. Assim, a literatura, enquanto sistema de representação, encarna a reprodução complexa dessa experiência crescente no país nos mais diversos espaços (interior, campo, sertão ou cidade) por meio da escrita artística.

Nessa linha de reflexão acerca dos contextos que possibilitaram a literatura problematizar a violência, Pellegrini (2008) evidencia que a representação da violência na literatura brasileira se efetivou a partir de duas vertentes bastante exploradas: a chamada "literatura regionalista" - estruturada em torno de uma realidade social em que viceja um sistema simbólico calcado em torno do ódio e da vingança individual - e a "literatura urbana", que surge a partir do ponto de vista da cidade como um centro modernizador, uma espécie de polo da legalidade.

Outro aspecto importante trazido à baila pela estudiosa se refere à peculiaridade de a literatura brasileira passar por espaços de exclusão, tais como os cortiços e casas de pensão. "As formas de violência ali representadas obedeciam aos códigos estéticos da época, compreendidos como a simbolização mimética determinista de conflitos sociais que brotavam do submundo dos centros urbanos de então" (PELLEGRINI, 2008, p. 44). Como protagonista da feição performática, a violência ecoa na literatura a partir dos anos 60 como uma vertente bastante fértil. Assumindo uma postura exibicionista com traços naturalistas, o cenário urbano passa a ser um espaço privilegiado, porque possibilita a indagação dessa própria ideia de urbanidade, pois esse espaço tido como polo modernizador e representante 
da organização e da racionalidade, também se apresenta como um espaço de conflitos evidentemente onde ocorrem as mais diversas formas de violência social.

Avançando em nossas teorizações, recorremos às definições de Cury (2007). A autora afirma que a literatura brasileira contemporânea tem suas raízes fincadas no solo urbano, mostrando obras em que a substituição do cenário rural pela vida agitada e violenta das grandes cidades é uma recorrente. "O espaço da cidade assume feição performática, exibido em cenas rápidas, sketches que rompem com formas enunciativas consagradas, deslocando técnicas de gêneros narrativos, sob o olhar de narradores também eles condenados ao seu movimento vertiginoso" (CURY, 2007, p. 10). A autora revela ainda que a partir dessa problematização institucionalizada de se definir a gênese dessa vertente literária, há uma forte imposição de um desafio para a crítica literária cuja tarefa é agrupar e avaliar o conjunto de obras publicadas na contemporaneidade. "Tais textos formam verdadeiros mapas literários, que intercambiam suas fronteiras, partilhando caracterizações e desenhando novas geografias da nossa literatura" (CURY, 2007, p. 08).

No que tange às especificidades da literatura contemporânea brasileira, pode- se constatar a existência de um espaço heterogêneo e diverso em que a brevidade de formas e a revitalização de gêneros associada ao emprego da estética da violência emerge como expressões fortíssimas dessa arte, o que revela, diante desse espaço plural, a impossibilidade de inclusão ou a instituição de uma única vertente literária.

Como esclarece Brandileone (2013, p. 17):

De todas as conjecturas possíveis sobre a literatura brasileira contemporânea, a única certamente indiscutível é a de que ela é extremamente diversificada. Também é certo que a diversidade é marca de qualquer período artístico, tendo em vista que a homogeneidade não existe, sobretudo no campo das produções artísticas.

O ponto de vista de Brandileone (2013) pode ser associado ao fato de na contemporaneidade a literatura se mostrar em seu aspecto multifacetado com uma profusão de temas e de técnicas. Dessa forma, pode se até atribuir um certo status de experimentação devido à quantidade de formas e de modalidades narrativas, que acabam refletindo uma 
literatura cada vez mais fragmentária. Ao retratar temáticas sociais e ficcionalizar dramas de personagens esquecidos, a literatura representa uma realidade.

A esse fato, Candido (1987) denomina de legitimação de pluralidade:

\begin{abstract}
Não se trata mais de coexistência pacífica das diversas modalidades de romance e conto, mas do desdobramento destes gêneros, que na verdade deixam de ser gêneros, incorporando técnicas e linguagens nunca dantes imaginadas dentro de suas fronteiras. Resultam textos indefiníveis: romances que mais parecem reportagens; contos que não se distinguem de poemas ou crônicas, semeados de sinais e fotomontagens; autobiografias com tonalidade e técnica de romance; narrativas que são cenas de teatro; textos feitos com a justaposição de recortes, documentos, lembranças, reflexões de toda a sorte. A ficção recebe na carne mais sensível o impacto do boom jornalístico moderno, do espantoso incremento (CANDIDO, 1987, p. 209210).
\end{abstract}

Sobressai no ponto de vista de Candido (1987), a visão de que a literatura contemporânea está imbuída de uma série de peculiaridades, tais como o emprego de narrativas curtas, a incorporação de técnicas de legitimação da pluralidade, a desestruturação do enredo e a ficcionalização de outros gêneros. O que o crítico nos apresenta é o aspecto plural da literatura brasileira, diagnóstico assinalado por Resende (2008) como multiplicidade: “são múltiplos tons e temas, e, sobretudo, múltiplas convicções sobre o que é literatura [...] (RESENDE, 2008, p. 18).

Para Candido (1987), o gênero conto é visto como a expressão que melhor representa a ficção literária mais recente. Para tanto, o crítico destaca como características desse gênero o emprego de técnicas renovadoras e a reabilitação, deslocamento do gênero, que incorpora técnicas antigas. Nesse contexto, o ponto de vista de Brandileone e Patrocínio (2018) pode ser adotado para se pensar acerca da produção literária contemporânea: "Esta fusão de gêneros, técnicas e linguagens resulta, muitas vezes, em textos indefinidos, os quais se acomodam dentro do universo literário situado entre a tradição e renovação" (BRANDILEONE; PATROCÍNIO, 2018, p. 25). Ampliando essa definição, convém destacar, ainda, conforme Luis Carlos Simon (1999) as peculiaridades do gênero conto na contemporaneidade. Em conformidade com o estudioso, essa narrativa pode ser encarada a partir 
de três características: a fragmentação, a velocidade e a intensidade. A fragmentação pode ser vista a partir da adoção de um enredo desestruturado. Para Simon (1999), essa característica é um reflexo das personagens cada vez mais problemáticas e ambivalentes. Já a velocidade e a intensidade se apresentam refletidas como traço do ritmo frenético do modo de vida contemporâneo, o que resulta em textos cada vez mais miniaturizados.

Ainda que Simon (1999) atribua essas características ao gênero conto, o romance produzido a partir do século XXI também se mostra muito próximo de tais características, como é o caso da obra As Fantasias Eletivas. Cury (2007), ao fornecer um breve diagnóstico acerca das características da produção literária recente, evidencia como traços estilísticos dos textos contemporâneos a rapidez, a concisão e a brevidade. Para a estudiosa, tais características evidenciam um cenário perpassado por inúmeros fluxos além de revelar no âmbito da escrita aspecto da renovação de gêneros nesse cenário múltiplo: "são textos que chegam, muitas vezes, a constituir um gênero literário novo, modulado numa narrativa formalmente marcada pela concisão e rapidez, como registros ininterruptos de realidades em movimento célere e que não têm repouso" (CURY, 2007, p. 11).

Essa colocação da autora vem ao encontro das tessituras fornecidas por Regina Dalcastagnè (2012, p. 110): “o espaço da narrativa atual é essencialmente urbano, ou, melhor, é a grande cidade, deixando para trás tanto o mundo rural quanto os vilarejos interioranos". O ponto de vista de Dalcastagnè (2012) pode ser explicado quando se constata que a literatura contemporânea brasileira acompanhou o processo de urbanização das cidades, que, na década de 1960, registrava cerca de 45\% da população do país vivendo na área urbana, mas, com base no censo 2010, do Instituto Brasileiro de Geografia e Estatística (IBGE), atualmente, 84\% da população do país vive nas cidades. Como consequência dessas alterações empreendidas no cenário brasileiro, a literatura, enquanto discurso, deslocou sua representação às dificuldades de adaptação do homem ao espaço urbano, fato responsável pelo surgimento de novos problemas, dentre eles, a desterritorialização.

Escrito pelo catarinense Carlos Henrique Schroeder, o romance As Fantasias Eletivas foi lançado no segundo semestre de 2014. Originado a partir do conto Os recepcionistas, 
constitui-se como o $10^{\circ}$ livro da carreira do autor. O romance narra a trajetória de duas personagens: Renê, um recepcionista de hotel e Copi, uma travesti argentina, que se prostitui a fim de sobreviver. As duas personagens têm em comum a trajetória de deslocamento e de fragmentação típicas do sujeito contemporâneo.

O romance está estruturado em quatro partes. A primeira intitula-se $S$ de Sangue. Apresenta a trajetória e o encontro entre as duas personagens na cidade de Camboriú. A segunda intitula-se A Solidão das Coisas e corresponde aos contos escritos a partir das fotografias tiradas com a câmera Polaroid. Os aspectos são múltiplos, indo desde um pino de alarme pendurado ou uma placa de trânsito, um telefone público. Por meio desses registros feitos por Copi, a personagem escreve narrativas curtas, as quais revelam uma grande amplitude temática servindo para reforçar o caráter fragmentado dessa personagem, uma vez que sua atitude pode ser compreendida como a de um escritor buscando linguagem própria para sua criação. Na sequência, tem-se Poesia Completa de Copi e a última parte recebe o título da obra: As Fantasias Eletivas. Correspondendo à fertilidade tratada pelos estudiosos da ficção contemporânea como uma das características de nossa literatura, essa parte estrutura-se a partir de uma carta em que Copi escreve para a mãe sobre todas as vontades não consumadas, podendo ser vista também como uma continuidade de apresentação dos fatos vividos pelo protagonista sem a presença de Copi, que acaba cometendo suicídio. Nesse aspecto, o livro ganha uma dimensão estilística peculiar, uma vez que além de evidenciar a fragmentação, a intensidade, a velocidade, sobressai a metalinguagem, já que se recorre à linguagem para ficcionalizar e tratar de fatos que não ocorreram.

A trajetória da personagem Renê revela um processo de despersonalização do sujeito. O autor, ao fazer uso de uma linguagem ágil, praticamente, elimina a presença mediadora de uma narrador.

O leitor já nas primeiras linhas do romance já é apresentado ao protagonista Renê:

Chegou rubro ao banheiro, lavou o rosto, olhou-se no espelho. Precisava se controlar, não podia colocar tudo a perder de novo, ela não merecia. Mas era como uma chave de fenda, que ia ao fundo, dilacerando o peito. E chorou mais uma vez, por ser fraco, por não controlar esse monstro, por não estar curado. Seria esta a palavra 
correta, curado? Como se cura algo que é de sua natureza? Como se separam óleo e água depois de misturados? Estragara sua vida de tal maneira havia alguns anos que, quando se entregou para o mar, nem as ondas o quiseram, e uma onda furiosa o devolveu para a areia. Cuspido pelo mar e pela morte, lhe restava levantar e caminhar. Será que ela estaria lá ainda? [...] (SCHROEDER, 2014, p. 13).

Assim, de modo intenso e veloz, o leitor é apresentado ao personagem Renê. Por meio da representação de suas ações, percebe-se sua fragmentação, visto que o ciúme doentio com que se relaciona com as pessoas é uma problemática que o acompanha desde criança como se pode perceber no trecho transcrito: "lembrou de sua mãe e da primeira vez que sentiu ciúmes, quando seu irmão mais velho ganhou o melhor presente do pai, o maior carinho da mãe. Tudo isso foi há muito tempo, num Natal qualquer" (SCHROEDER, 2014, p. 14).

Divorciado, o protagonista, quase matou o filho e a ex-esposa, além de ter tentado o suicídio e não ter conseguido. Por esse motivo, a personagem é obrigada a viver isolada da família mudando-se para Santa Catarina na cidade de Balneário Camboriú a fim de reconstruir sua vida. Nessa cidade turística, Renê torna-se recepcionista de um hotel e passa boa parte do tempo limpando o tampo de granito da mesa da recepção com álcool, motivo pelo qual acaba recebendo o apelido de Mister Álcool.

Na obra de Schroeder, emerge-se o vazio do espaço urbano, uma vez que a cidade aflora como um espaço opressor. Regina Dalcastagnè (2003), ao analisar o espaço na ficção contemporânea, ressalta que esse componente da narrativa é representado como um espaço sufocante devido a peculiaridade de se ter superado a condição agrária:

A cidade é um símbolo da sociabilidade humana, lugar de encontro e de vida em comum - e, neste sentido, seu modelo é a polis grega. Mas é também um símbolo da diversidade humana, em que convivem massas de pessoas que não se conhecem, não se reconhecem ou mesmo se hostilizam; e aqui o modelo não é mais a cidade grega, e sim Babel (DALCASTAGNÈ, 2003, p. 34).

Na narrativa de Schroeder, o espaço urbano é a cidade turística de Balneário Camboriú, descrita de forma muito semelhante às metrópoles como São Paulo e Rio de Janeiro, 
espaços já amplamente retratados em seus múltiplos espaços de exclusão. Como uma forma de desterritorialização, a cidade turística de Balneário Camboriú é retratada de modo a enfocar um aspecto menos idílico desse cenário. "Neste sentido, temos um pálido retrato da vida fervilhante, desconfortável e violenta de nossas cidades" (DALCASTAGNÈ, 2003, p. 50).

Dito isso, salientamos a forma marginalizada e tumultuada como é descrita a cidade: "numa cidade turística tudo tem preço, informação, prazer, sossego, vingança. E Renê sabia disso, e estava fora dos esquemas mais pesados, pois tinha medo, sobretudo da cadeia" (SCHROEDER, 2014, p. 36). A partir desse trecho, pode-se compreender que esse espaço retratado em sua forma desordeira, abre novas possibilidades de representação nesse cenário marcado pela globalização. O narrador descreve a cidade como "um aglomerado de prédios em menos de cinquenta quilômetros quadrados, que recebia mais de um milhão de turistas por ano na alta e média temporada, e era um dos principais destinos turísticos de Santa Catarina” (SCHROEDER, 2014, p. 36). Justamente, nesse cenário, um dos principais pontos turísticos de Santa Catarina, é eleito por Renê como um lugar propício para se recomeçar, onde "muitas pessoas vinham para enterrar seu passado, como acontece com Renê e Copi.

Nesse sentido, pode-se compreender o romance como uma forma de estruturar de a solidão e a violência como componentes estéticos desse novo modo de vida contemporâneo marcado pelo espaço urbano, responsável por abrigar pessoas com identidades múltiplas. Assim, é muito comum na representação da literatura contemporânea a perda do contato humano, a fragilidade nas relações diárias e a decomposição identitária das personagens. Tais aspectos são facilmente perceptíveis no romance cotejado. Descrito como ciumento, Renê, o protagonista, teve várias namoradas, mas não consegue manter um relacionamento duradouro com nenhuma delas.

Já nas primeiras páginas do livro, quando se apresenta a personagem e o espaço onde ele vive, leitor é exposto a uma cena de violência caracterizadora da vertente dita marginal, o que comprova o quão problemático o cenário urbano se constitui na atualidade: 
Olhou para trás e viu um rapaz magro, de cabeça baixa, usando uma camisa surrada e um boné que lhe cobria os olhos. E quando viu a faca na mão, o desconhecido já estava a um metro. Renê deu um passo para trás e virou-se rapidamente para o lado, e sentiu uma terrível ardência na barriga, como um corte mergulhado em álcool. Viu a faca cair no chão: era de cozinha, aquelas pequenas, de serra. Queriam mesmo machucá-lo. E aí viu os olhos do agressor, não havia dor, não havia raiva.

"É um aviso, um lembrete, mermão, é pá deixá a Seca na dela. Some, sacô?” (SCHROEDER, 2014, p. 17).

O trecho do romance, assinala as consequências de se viver num espaço corrompido e problemático da cidade onde vicejam desafios típicos de uma sociedade problemática. Sobressai no trecho a incorporação do discurso contemporâneo literário em dialogar com o espaço fluido e múltiplo de indivíduos problemáticos em uma sociedade cada vez mais fragmentada. Dessa forma, essa violência elevada de forma prosaica na sociedade acaba sendo refletida e refretada em seu momento estético. No excerto em questão, ganha destaque estilístico a forma como foi intercalada as vozes narrativas. O ponto de vista do narrador, ao apresentar as situações de violência a que Renê se torna vítima, pauta por um discurso perpassado pela linguagem culta e com uma narrativa precisa em suas ações, que parecem criar uma poética do acontecimento. Na sequência, a voz narrativa, para situar o ponto de vista do sujeito agente vale-se de um léxico intenso e veloz, o que acaba criando por meio dessa escolha léxica intensa e veloz um efeito estético que propicia uma reflexão acerca dessa escolha estilística. Dessa forma, a partir dessa intensidade, salienta-se a incorporação no romance de uma linguagem capaz de refletir uma forma de desumanização, inconformismo e efemeridade no mundo em ruínas.

\section{Considerações Finais}

Sobressai na narrativa contemporânea a reconfiguração do espaço urbano, uma vez que sua representação é feita de modo corrompido e problemático. A crítica Regina Dalcastagnè (2003), ao tratar acerca da constituição do espaço na narrativa contemporânea, afirma que se trata de um ambiente representado de forma sufocante pelo simples fato de 
não existir mais o território unificador e comum da epopeia. Longe de esgotar as possibilidades de análise do romance As Fantasias Eletivas, o presente artigo pautou-se em apontar alguns aspectos atinentes à contemporaneidade que são representados pela obra, tais como a fragmentação, a intensidade e a violência.

Como característica desse período, a narrativa é marcada pelo esfacelamento, pela fragmentação, pela velocidade e pela intensidade. Assim, emerge uma narrativa calcada na brevidade, na concisão e em recursos que dão voz e vez para as personagens subalternas marcados pela dubiedade e por todas as incertezas de um sujeito em crise. No romance $A s$ fantasias eletivas, observamos esses aspectos, uma vez que a personagem protagonista é representada de maneira problemática. Obrigado a se deslocar de sua verdadeira cidade, Renê passa a viver transitoriamente em Santa Catarina, o que mostra o caráter de fluxos existente na sociedade globalizada e como esse sujeito transita nesse espaço de modo a sentir deslocado. Essa é a realizada de Renê, personagem distante do grupo dominante e, momentaneamente, sem um grupo pertencente, exerce o ofício de recepcionista em um hotel, integra uma rede de pessoas que exploram as atividades ilícitas, como prostituição e tráfico, em uma cidade turística.

No que tange aos aspectos estilísticos, ainda que de forma breve, podemos destacar a preponderância de uma narrativa curta, a incorporação de técnicas de legitimação da pluralidade bem como a desestruturação do enredo e a revitalização de outros gêneros, revelando uma narrativa híbrida. Essa última característica pode ser observada na última parte da obra delineada por um traço metalinguístico. Com essa perspectiva múltipla, salientamos que o romance tematiza a caracterização de sujeitos em crise de modo a representar esse mosaico de identidades a que os sujeitos estão confinados na contemporaneidade. 


\title{
IN THE AGE OF MULTIPLICITY: \\ FRAGMENTATION, INTENSITY AND VIOLENCE IN ROMANCE THE ELEVENTH FANTASIES
}

\begin{abstract}
Contemporary texts can be presented under the label of speed, brevity and brevity. In this way, a multiplicity of tendencies predominates and forms that do not necessarily need to overlap one another, but rather to live harmoniously. From this initial considerations, this article proposes to analyze the novel The Elective Fantasies. Therefore, we seek to study how fragmentation, intensity and violence occur in this narrative. As theoretical subsidies, the works of Antonio Candido (1987; 2003), Beatriz Resende (2008; 2015), Tânia Pellegrini (2008), Ana Paula Franco Nobile Brandileone (2013) and others were used.
\end{abstract}

KEY WORDS: Contemporary Brazilian Literature; Fragmentation; Identity; Violence.

\section{REFERÊNCIAS}

BRANDILEONE, Ana Paula Franco Nobile; PATROCÍNIO, Paulo Roberto Tonani do. Os ricos também morrem, de Ferréz: Por uma dicção Lírico-prosaica do universo periférico. In: OLIVEIRA, Vanderléia da Silva; VALENTE, Thiago Alves. Desafios contemporâneos: novas leituras. Campinas, SP: Pontes Editores, 2018.

BRANDILEONE, Ana Paula Nobile. Literatura brasileira contemporânea: caminhos diversos. In: BRANDILEONE, Ana Paula Nobile; OLIVEIRA, Vanderléia da Silva (Org.). Desafios contemporâneos: a escrita do agora. São Paulo: Annablume, 2013. p. 17-33

CANDIDO, Antonio. A educação pela noite \&outros ensaios. São Paulo: Ática, 1989.

CANDIDO, Antonio. Vários escritos. $3^{\mathrm{a}}$ ed. São Paulo: Duas cidades, 2003.

CURY, Maria Zilda Ferreira. Novas geografias narrativas. Revista Letras de Hoje. Curso de Pós-graduação em Letras. Porto Alegre: EDIPUCRS, v. 42, n. 4, p. 7-17, 2007.

DALCASTAGNÈ, Regina. Literatura brasileira contemporânea: um território contestado. Rio de Janeiro: Editora da UERJ; Vinhedo: Horizonte, 2012.

DALCASTAGNÈ, Regina. Sombras da cidade: o espaço na narrativa brasileira contemporânea. Revista de Estudos de Literatura Brasileira Contemporânea, n. 1. Brasília, jan/jun. 2003, p. 33-53. Disponível em: <http://repositorio.unb.br/bitstream/10482/9619/1/A RTIGO_SombrasCidadesEspa\%C3\%A7o.pdf>. Acesso em: 03 fev. 2019.

PELLEGRINI, Tânia. No fio da navalha: literatura e violência no Brasil de hoje. In: DALCASTAGNÈ, Regina (org.). Ver e imaginar o outro: alteridade, desigualdade, violência na literatura brasileira contemporânea. São Paulo: Horizonte, 2008. p. 41-56. 
RESENDE, Beatriz. A Literatura Brasileira num mundo de fluxos. Revista Terceira Margem. Rio de Janeiro, Número 23, p. 103-112.

RESENDE, Beatriz. Contemporâneos: expressões da literatura brasileira no século XXI. Rio de Janeiro: Casa da palavra/Biblioteca Nacional, 2008.

SCHROEDER, Carlos Henrique. As fantasias eletivas. Rio de Janeiro: Record, 2014.

SIMON, Luiz Carlos Santos. Além do visivel: contos brasileiros e imagens na era do pós-moderno. Rio de Janeiro: UFRJ, 1999. Tese de Doutorado em Literatura Comparada.

Recebido em: 03/05/2019.

Aprovado em: 31/07/2019. 